\title{
PSYCHOLOGICAL SCIENCES
}

\section{POSITIVE AND NEGATIVE ASPECTS OF THE SOCIAL MEDIA INFLUENCE ON VALUE ORIENTATIONS IN ADOLESCENCE}

\section{Larusa Bobrova ${ }^{1}$}

DOI: https://doi.org/10.30525/978-9934-26-076-6-22

Today it is impossible to imagine human life without social media networks. They penetrate all spheres of life and qualitatively change the nature of our interaction. Social media allows us to be creative, create different kinds of content, promote ourselves, develop our own brands and become known opinion leaders. Every day Internet users sign up for new social networks and become active in their virtual lives. This helps everyone feel integrated into the social life of society. At the same time, social networks include a real threat to the formation of worldviews, moral qualities and life values. This is relevant for the present time, because the COVID-19 pandemic has practically moved our lives to the Internet.

In psychological science there is no unified approach to the interpretation of the social network. The considered theoretical concepts unite its understanding as an interactive website, the content of which is filled by the network users themselves. The site is an automated social environment that allows a group of users united by common interests to communicate [3].

It has been established that social networks create not only opportunities for developing abilities, improving knowledge and expanding the range of interests, but also contain real threats to personal development, including Internet addiction, saving or lack of time for real communication and so on. Social networks, overshadowing the classical institutions of socialization family, school, friends - have a dominant role in the process of personality socialization and have a direct impact on its value orientations.

In modern psychology value orientations are considered as a complex socio-psychological phenomenon that characterizes the orientation and content of the activity of the individual, determines the overall approach of the person to the world, to oneself, gives meaning and direction to personal positions, behaviors, actions. The system of value orientations has a multilevel structure. At its apex are values associated with the idealization and life goals of the individual [4].

\footnotetext{
${ }^{1}$ National Pedagogical Dragomanov University, Ukraine
} 
Researchers identify different components in the structure of value orientations, in particular: motivational and value based, cognitive, emotional and volitional. The system of values and value orientations is characterized by a dynamic, changing nature of development, based on the interaction of two contradictory trends: the tendency to preserve and the tendency to change the system [2].

Adolescence is particularly sensitive to the impact of information technology in general and, in particular, to virtual communication through the defining role of communication and self-determination of the individual during this period. It is in adolescence that a stable circle of interests begins to form, which is the psychological basis for the development of personal value orientations [1].

Analysis of the results of the empirical study showed that the specificity of value orientations projection by the personality of adolescence is determined by the influence of social networks and the ability to subjectively manage their translation. Thus, the experimental study found that $60 \%$ of the respondents are characterized by excessive interest in social networks. These respondents communicate with friends, listen to their favorite music and seek information about different areas of life. The terminal values of creativity, cognition, development, interesting work, and health are significant for these young men. Among the instrumental values, the following are significant for these users: cheerfulness, independence, honesty, and education. During the quarantine, respondents in this group attended concerts and theaters online, preferred marathons to expand their personal potential, and used social networks as a platform for professional activities. Such users noted, «If it were not for social media, it would be difficult to navigate in today's society».

The results of the study showed the presence of Internet addiction of students (5\%). These students play games, watch movies, listen to music and sometimes communicate with friends, but they do not use their time in social networks for personal development.

The following terminal values were significant for them: entertainment (a pleasant, carefree pastime, absence of duties), intransigence to one's own flaws and to the flaws of others, and the value of loyal friends. Among the instrumental values significant for this group of students are courage in defense of their own position and independence. During quarantine, these students favored online parties and entertainment content among bloggers and stars.

It was found that $35 \%$ of students are conscious social media users. They are on social media to find interesting and useful information, communicate with friends. Sometimes they spend time to watch movies. Users of this group understand not only the positive impact of social networks, but also consider the negative consequences of online communication. For these respondents 
important values are: health, love, having good and loyal friends, development, and material security. Among instrumental values significant for this group of users are: responsibility, self-control, developed will. During the quarantine these students used social networks rationally. They appreciate the opportunity to join different types of art and learn new things for themselves through social media. Respondents in this group noted, «What I find on social networks inspires me to my own creativity, so I primarily subscribe to accounts that are creative, interesting, and similar to my field of work».

The majority of respondents noted that social networks actively influence various aspects of their life activities. This influence cannot be unequivocally qualified as a positive or negative phenomenon. The use of social networks positively influences the realization of creative ideas, promotes selfexpression, active interaction with others, helps to implement professional and educational activities, broadens the horizons, etc. Despite a number of advantages, the researched noted the problems that accompany the use of social networks. In particular, the constant stay in the network takes a lot of time and distracts from other duties, negatively affects the process of socialization through the reduction of direct social interaction, leads to negative changes in communication with friends and relatives, affects the development of depression, leads to a reassessment of established values.

\section{References:}

1. Babenko Yu. A. (2013) Viljnyj chas i dozvillja ukrajinsjkoji molodi v umovakh novoji sociokuljturnoji realjnosti [Free time and leisure of Ukrainian youth in the new socio-cultural reality]. Bulletin of the National Academy of leading personnel of culture and arts, no. 2, pp. 74-79.

2. Butkivska T. V. (1997) Problema tsinnostei u sotsialisatsii osobystosti [The problem of values in the socialization of personality]. Values of education and upbringing [Values of education and upbringing]. Kyiv, pp. 27-31. (in Ukrainian)

3. Voiskunsky A. E. (2000) Psychological aspects of human activity in the Internet environment. Proceedings of the 2nd Russian Conference on Environmental Psychology: Abstracts. Moscow: Ecopsiscentr ROSS, pp. 269-270.

4. Danko Yu. A. (2012) Social networks as a form of modern communication: pros and cons. Modern Society: Political Science, Sociological Sciences, Cultural Sciences, pp. 179-184. 